\title{
Libraries and Health Literacy Campaigns as Veritable Tools for Curtailment of COVID- 19 in Nigeria
}

\author{
Mathew Adesanmi FARUKUOYE CLN ${ }^{1 *}$ Sunday Olurotimi OBADARE CLN ${ }^{2}$ \\ 1.College Library, College of Health Sciences and Technology Ijero-Ekiti, Ekiti State, Nigeria \\ 2.Hezekiah Oluwasanmi Library, Obafemi Awolowo University Ile-Ife, Osun State, Nigeria
}

\begin{abstract}
Health literacy is an important aspect of preventive measures in curtailing the spread of diseases in the society. This is due to the fact that a health literate person understands his/her health status, take prevention and control measures of various diseases. The purpose of this paper was to discuss how libraries and deployment of health literacy campaigns can prevent, control and curtail the spread of Coronavirus (COVID-19) in Nigeria. The researchers reviewed several literatures and found out that libraries have a big role to play to ensure that community recognises their information needs, search for relevant information and make use of the information to make informed health decisions. The study concluded that COVID-19 imposes a double burden of health emergency and economic crisis on government and the people. Therefore, it becomes imperative for all stakeholders including the libraries to be deeply involved in health literacy campaigns in order to curtail the spread of the pandemic code named COVID-19 in Nigeria.
\end{abstract}

Keywords: Health Literacy, Libraries, COVID-19, Nigeria

DOI: $10.7176 / \mathrm{JEP} / 11-17-08$

Publication date:June 30th 2020

\section{Introduction}

The World Health Organisation defines health literacy as cognitive and social skills determining individuals' motivation and ability to receive, understand, and use information in a health-promoting manner. Health literacy as an outcome of health promotion (Nutbeam, 2000) has been defined differently by many authors (Wickline and Rosenthal, 2010; Dodson et al., 2015; Osborne, 2012). Wickline and Rosenthal (2010) defines health literacy as the ability to locate medical facilities, schedule and keep appointments, describe, monitor, and measure symptoms, follow prescribed medication or treatment regimens, adjust medications or treatment as needed, seek care when appropriate, determine risk and take preventive actions. According to Dodson et al., (2015), health literacy means motivation and ability of individuals to gain access to, understand and use information in ways which promote and maintain good health. Osborne (2012) says that health literacy involves two parts - patients or anyone receiving health communication and providers or anyone giving end health communication.

While some authors see health literacy as being important to patients, others see it as an important thing to all people in the community regardless of their health status. The later perception insists on preventive (most cost effective) and control mechanisms for diseases, while the earlier show that health literacy is for people who are already affected by diseases (Mnzava and Katabalwa, 2017). Since people need to stay safe and healthy amidst the crisis of COVID-19 that is looming danger all over the world, health literacy then becomes an important thing to everyone. This is mainly because in many cases health literacy is related to the health status of patients and community at large (Tang et al., 2008; and Sanders et al., 2009). Health literacy is also linked to economic development such that people with low health literacy do not have the ability to engage effectively in socio economic activities due to poor health status (Mnzava and Katabalwa, 2017).

However, the responsibility of achieving higher literacy rates cuts across multiple boundaries, professions sectors (WHO, 2013). Initiatives to build health literacy in Nigeria must therefore include academic and business communities' health care facilities, faith-based organization, news and electronic media, adult educators and literacy practitioners, community-based organisations, and government agencies educators and government agencies, educators and health communicators and the general public (Rootman, 2012). The collective efforts of these groups led by librarians will surely put Nigeria on a strong footing to raise literacy levels (Nwafor-Orizu, 2020) and that will go a long way in curtailing the spread of COVID 19 in the country. Improved health literacy is considered critical to the achievement of health and development (WHO, 2009).

\section{The magnitude of corona virus (COVID-19) in Nigeria: the index case of COVID-19 in Nigeria}

Coronavirus disease (COVID-19) is an infectious disease caused by a newly discovered coronavirus and mode of transmission of the virus is from person to person via respiratory droplets. The virus spread through multiple modes like touching, kissing, coughing and sneezing. Most people infected with the COVID-19 virus will experience mild to moderate respiratory illness. Older people and those with underlying medical problems like cardiovascular disease, diabetes, chronic respiratory disease, and cancer are more likely to develop serious illness. The coronavirus belongs to a family of virus that may cause various symptoms such as pneumonia, fever, 
breathing difficulty and lung infection (WMHC, 2020). The World Health Organisation (WHO) used the term 2019 novel coronavirus to refer to a coronavirus that affected the lower respiratory tract of patients with pneumonia in Wuhan, China on 29 December 2019 (WHO, 2020). The WHO announced that the official name of the 2019 novel coronavirus is coronavirus disease (COVID-19) (WHO, 2020). And the current reference name for the virus is severe acute respiratory syndrome coronavirus 2 (SARS- CoV-2).

The novel Coronavirus disease infection (COVID-19) first started in China in Dec 2019 and a few months spread to almost all countries of the world. The infection was declared by the World Health Organisation as a global pandemic in March 2020 (WHO, 2020). As of May 23, the confirmed worldwide cases for the virus have surpassed four million with the current figure being at 5,269,965 and over 338,191 deaths had been reported globally with the majority of the infections and deaths reported from Western Europe and North America (Worldmeter, 2020). The unprecedented pandemic has led many countries to declare it as a public health emergency with the implementation of far-reaching measures to curb its spread including travel restrictions, emergency response procedures, and even entire country lockdowns.

The COVID-19 pandemic has spread to more than 114 countries before it was officially declared as a pandemic by the WHO on the 11th March 2020 (Anjorin AA, 2020). In the Sub-Saharan Africa region, despite a late arrival, the COVID-19 outbreak has spread rapidly across the region in recent weeks. As of May 22, 57,820 active cases of COVID-19 were confirmed in 45 countries in Sub-Saharan Africa. A relatively small but rising number of confirmed cases are now due to local transmission. The lack of testing capacity in many countries suggests that these figures most likely understate the true number of infections. South Africa has the largest outbreak in the region with 20,135 confirmed cases and 397 deaths as at the 23rd of May 2020 (WHO, 2020). It has declared a national state of disaster and announced a number of measures to curb the spread of the virus, including a travel ban on foreign nationals from high-risk countries, prohibition of public gathering of more than 100 people, and school closures. Rising outbreaks, although smaller in magnitude to that of South Africa, have also emerged in West Africa (Burkina Faso, Côte d'Ivoire, Senegal, Ghana, and Nigeria) and East Africa (Rwanda and Kenya). These developments have prompted governments to put in place their own containment measures, including travel bans on foreigners from countries that have reported any case of COVID-19, restrictions on public assemblies, and school closings. These containment measures may prove insufficient in stemming the outbreak without the appropriate health interventions and population response. (Calderon, Cesar et al., 2020). Here, the first set of index cases in Africa, Egypt recorded the first confirmed case on the 14th February 2020, followed by Algeria on the 25th February 2020. Nigeria recorded her index case on the 27th February 2020 (WHO-Afro). In Nigeria, after the confirmation of the first case on the 27th February 2020, and for the first time, researchers from the Centre for Human and Zoonotic Virology in Lagos University Teaching Hospital/College of Medicine of the University of Lagos, African Centre for Genomics of Infectious Diseases in Reedemers University and the Nigeria Institute of Medical Research Lagos successfully perform the genome sequencing of COVID-19 (Anjorin AA, 2020). According to the Nigeria Centre for Disease Control, a second confirmed case was detected in the country on the 9th March 2020. This case was a contact of the index case. Out of a total of number of people screened for COVID-19 so far in Nigeria, as at 23rd May 2020 there are 7,016 confirmed cases from 35 States of Anambra, Imo, Plateau, Bayelsa, Ebonyi, Kebbi, Nasarawa, Yobe, Adamawa, Benue, Sokoto, Zamfara, Abia, Niger, Enugu, Jigawa, Ondo, Delta, Kaduna, Akwa-Ibom, Kwara, Borno, Katsina, Gombe, Taraba, Kano, Bauchi, Edo, Ekiti, Lagos, Ogun, Osun, Oyo, Rivers and the Federal Capital Territory. Lagos State with a current population of over 20 million is leading with over two thousand, five hundred confirmed cases. One hundred and ninety two deaths has been recorded in the country while one thousand seven hundred and thirty two cases including the index and first contact have been discharged to go home after testing negative to the virus twice consecutively [NCDC report].

The best way to prevent and slow down transmission is be well informed about the COVID-19 virus, the disease it causes and how it spreads. Given the spread of the new coronavirus and its impacts on human health it is expedient for countries to adhere strictly to experts' advisories and guidelines. According to the World Health Organisation, countries must detect, test, treat, isolate, trace every contact, and mobilise their citizens in the response. Those with a handful number of cases must prevent them from becoming clusters, and those clusters from becoming community transmission. All countries need to activate and scale up crisis response mechanisms: be in touch with the communities and how they can protect themselves, get the hospitals ready, and train the health workers (WHO, 2020). To facilitate the response mechanism of getting in touch with the communities as recommended by W.H.O and in delivery of aggressive risk communication strategies, the role of librarians is essential. This is supported by a report from Maanvi that San Francisco government has assembled an army of librarians, social workers, attorneys, investigators and medical students to find and warn anyone and everyone who may have been exposed to COVID-19 (Maanvi Singh, 2020). However, putting in place a system for tracing and tracking the contacts of people who have tested positive is an absolute essential pillar we need to build up and put in place before we even think about reopening the country.

However, this is a medical condition that is capable of being communicated by direct contact. Though 
COVID-19 is currently the leading causes of death in the United State, killing more people per day than previous top contenders like heart disease and cancer (live science, 2020) and it is a potential life loss in the world and Sub Saharan Africa is not an exemption. Apart from the fear and uncertainty about the spread of infections, people faced other challenges that could impact their health and psychological well-being including restriction, changes in their lifestyles, living conditions and jobs, closure of schools. This situation calls for special attention so as to rescue the life of people and for the economic development of individuals and the national in general. Based on the above gap, it is imperative for the stakeholders including the libraries to be deeply involved in health literacy campaigns in order to curtail the spread of the pandemic code named COVID-19 in Nigeria. There are a lot of libraries in Nigeria including academic libraries, public libraries, hospital libraries and other health centres. However, nothing is known about how these libraries involve themselves in health promotion except for some of the health libraries. This has motivated this study with the aim of discussing the role of libraries in curtailing this infectious disease in Nigeria.

\section{Materials and Methods}

A Community-driven approach was used for building the paper list used in this literature review. However, data for this paper was collected through the literature review whereby all papers with information about health literacy in curtailing the infectious diseases were collected and used in this study. Collection of papers was done using various online tools with relevant information including LibHub - a Library Gateway to Information resources (http://libhub.kiox.org), Google scholar (scholar.google.com) and World Health Organisation (WHO). The literature searching was conducted after three major steps; (i) Search formulation where the topic was analyzed to give key concepts (Health literacy, Libraries, Diseases, Coronavirus, COVID-19, Nigeria), (ii) Choosing the appropriate information sources, and (iii) Use the identified keywords in step (i) to conduct search in the LibHub, Google scholar and WHO databases. The searches were restricted to recent publications. Only search results which were found relevant to the topic- Libraries and Health Literacy campaigns as veritable tools for Curtailment of COVID-19 in Nigeria were selected and used.

\section{Results}

4.1. Libraries as strong partners in promoting health literacy in the prevention and spread of COVID-19

The role of library in promoting health literacy can not be overemphasized as libraries have been noted to support community development in various areas such as education, economic, research and health. It has been observed that libraries act as a bridge of information from information providers such as government, organizations and institutions to the people. Libraries are known to be the centre of knowledge which collects various information resources including health information resources for the users, local gateway to knowledge capable of providing basic conditions for lifelong learning, independent decision-making and cultural development of individuals as well as social groups (Ghosh, 2013). It is through libraries that some communities get informed on socio-economic matters.

Nigeria has many libraries which include public libraries, academic libraries, health libraries, research libraries and information centers. From another point of view the concept of library can be classified as digital library and virtual library (Atanu and Dhirtiman, 2018). Since the development of knowledge of society depends on the academic education through Schools then Colleges and ultimately Universities or Research Institutes. Scientific knowledge is gained through research and education both combined together. So to meet up with the users' needs and to make their thirst fulfilled even during global pandemic crisis as researchers are on their toes to proffer solutions on how to curtail the pandemic even when the physical libraries are closed, the need for change from the traditional to modern library providing best possible service is inevitable. However, the conceptual and psychological thinking of users have been witnessed which has led to change in the perception about the library. Now library is to serve beyond the boundaries of its building and country borders (Atanu G. \& Dhirtiman B. 2018).

Digital library: This is one kind of library that collects, organize and disseminate information through different electronic resources such as e-journals, e-books, video materials, audio materials, pictures, news clippings etc. Due to the massive implementation of Information Communication Technology now users can easily access the library from any corner of the world 24/7/365 through web. (Atanu G. \& Dhirtiman B. 2018). This has been so helpful especially during this time of COVID-19 pandemic where measures are strictest and libraries have either been forced to close or have chosen to do so following consideration of the risks to users and staff.

Virtual Library: it is mainly finding the record, managing the records and providing access to the records. According to the functions as mentioned, a virtual library is a set of links which resides elsewhere on the network and can be accessed from anywhere only through proper seamless network connection.

Now library is not only the store house of printed resources but also preserves different kinds of e-resources. Information generated, records stored, retrieved and disseminated in digital platform. This transformation 
changes the characteristics of classical library and converts into the modern library. Libraries operate fulfilling the need of its user community. The need for change is seen forcibly due to the looming danger posed by the emergence of the COVID-19 pandemic.

There are many types of libraries in Africa but nothing is known about how these libraries involve themselves in health promotion except for some of the health libraries. The study by Chipungahelo et al. (2015) support this by reporting that 25 health libraries were identified under the project of AHILA-Tanzania Chapter, the project which started in June 2013 and ended in September, 2013. These health libraries are playing a vital role in promoting health literacy. According to Chipungahelo et al. (2015) the AHILA-Tanzania Chapter supported health literacy promotions in which among other things it promoted relationship and network among health librarians and information professionals within the libraries and information centers in health settings, and carried out a number of activities such as preparing brochure with health information, recruiting members, trainings, developing a social media platform for easy communication and resource sharing among members. Libraries in the Sub Sahara region should continue these initiatives started by AHILA-Tanzania Chapter by promoting health literacy for combating diseases.

Libraries have the role of collecting vital, quality and relevant health information resources for curtailing Coronavirus (COVID-19). According to Obidike and Nkechi (2011), libraries should collect and compile health information, store them in suitable media which can be easily accessed by policy and decision-makers as well as other health information users. Librarians are advised to partner with community health workers which include medical doctors or veterinary doctors and other health personnel in order to gain access on vital health information issues for health development and disease awareness (Obidike and Nkechi, 2011). Chipungahelo et al. (2015) argue that libraries are able to collect vital health information, including information resources on how to avoid the circumstances that cause health problems, and on providing preventative health programs and treatment programs. Libraries should be able to harness and store relevant health information resources which can help in curtailing the spread of Coronavirus.

Promotion of health information resources is important in order to raise awareness of COVID-19 and how to curtail it. It is the obligation of public libraries, academic libraries as well as health libraries to provide accessible and reliable health information sources and services to the community (Orban, 2005). According to Ghosh, (2013) libraries and health centers can help in disseminating health care information to unprivileged communities especially the rural communities. It is the role of health librarians or health information officers to promote and enhance access health information as they are capable of providing needed assistance through training and through the selection, repackaging, and dissemination of relevant materials (Chipungahelo et al., 2015). Libraries should disseminate health information about the causative agent of Coronavirus and preventive measures. Promotion of health information should be made by using brochures, leaflet, newspapers, magazines and others both in print and electronic formats which should be distributed to the public with the aim of increasing awareness about the disease and how to curtail it. Librarians have the role of promoting health information literacy to all kinds of library users, in order to help many people have "the ability to recognize a health information need, identify likely information sources and use them to retrieve relevant information; assess the quality of the information and its applicability to a specific situation; and analyze, understand, and use the information to make good health decision" (Orban, 2005).

Libraries are supposed to provide training and health education to the community on health literacy for curtailing Coronavirus. They should organize seminars on health education (Obidike and Nkechi, 2011), the education which for example will help people to have attitudinal change and hence embrace the NCDC regulations in curtailing the spread of Coronavirus. The librarians should make sure they impart knowledge of health literacy for combating diseases to health information consumers (Chipungahelo et al., 2015). Moreover, like the way non communicable diseases is prevented (ECOSOC, 2010), librarians should provide training on how to use ICT devices to access health information for curtailing Coronavirus.

Apart from training and seminars, libraries particularly health libraries from health institutions in Nigeria can create an e-repository of systematic documentation of health information resources or virtual library of health promotion practice, which will include good practices and lesson learned, which will be consulted by practitioners, policy-makers and academicians (McQueen et al., 2014). The repositories will help various health information consumers to make best health decisions concerning Coronavirus and how to avoid it or curtail its spread. Also, the repositories will help health practitioners, doctors, researchers, decision makers and politicians to get useful information which in return will help them to make good decisions on how to protect the community and curtail community spread of COVID 19.

The experience from other countries shows that health promotion in the library is not a new thing. For instance, San Francisco government in the United State of America has assembled an army of librarians along side social workers, attorney, investigator and medical students to find and warn anyone and everyone who may have been exposed to COVID-19. It has put in place a system for tracing and tracking the contacts of people who have tested positive (Maanvi Singh, 2020). According to IFLA (n.d.) 81\% of local government library authorities 
in England provide access to e-information on health and wellbeing as well as literacy skills to support health literacy so as to improve access and use of health information. Public libraries are involved in informing the public about important health issues through speeches from doctors, nurses and other from health professionals as well as provision of special health services for the disabled (Parker and Kreps, 2005). In Botswana public libraries serve communities with health information through various ways such as outreach, library brochures/leaflets, newsletters and library exhibitions (Ntlotlang and Grand, 2016). Libraries are taking the centre role in the paradigm shift in health promotion. According to Libschultz (2004) libraries are both the symbol of stability and the embodiment of change. In the past, libraries offered a quiet space for reading, study and reflection. One was surrounded by collections of books, journals and other materials on many topics. Access to quality health information and material is a prerequisite to improving health care literacy. In this new era of change and technology, libraries and librarians have to be creative and assertive to ensure equal access to information that can enhance learning and decision making particularly in the community driven area of health care information.

\subsection{Opportunities which can be used by libraries in prevention and spread of COVID-19}

In our favour, technological advancements have made information more easily accessible than ever before as Information and Communication Technologies (ICT) provides immense opportunities to store, process, retrieve, disseminate and share information. It provides tools such as radio, telephone, mobile phones, newspapers, television and website which can be used to disseminate and share information aiming at curtailing the spread of the virus. The report by Chipungahelo et al. (2015) indicate that in Tanzania health information has been promoted and disseminated through library's websites, organization's websites, mass media, newspapers, meetings, exhibitions and other information communication materials. According to ECOSOC (2010) advance in ICT has made dissemination and access of information more possible as more information has been made available through the Internet and other multimedia formats, it is possible for electronic learning, the use of text messaging, web 2.0, and online social networks are becoming increasingly common in the daily lives of people even in some developing countries. Mobile devices such as smartphones, Personal Digital Assistants (PDAs), and laptops as well as wireless and satellite communications are giving remote communities an opportunity to be connected and have access to health information hence expanding the possibility of providing health literacy (ECOSOC, 2010). All these opportunities can be tapped by libraries to curtail COVID-19.

Another opportunity which can be used by libraries is its closeness to the community; public libraries and community libraries are a good example of this, also they serve diverse population in the community. Edwards and his fellow describe public libraries as a place where people get information and other services to sustain almost every aspect of life (Edwards et al., 2013).

Moreover, librarians' skills and knowledge in information and communication management when partnering with health professionals can best be utilised to promote health literacy (ECOSOC, 2010; Chipungahelo et al., 2015; Ghosh, 2013), this can also be employed particularly on COVID-19.

Changing relationship between information and users has avail library the opportunity to promote health literacy. As a result of COVID-19 pandemic, the direct relationship with leaders of learning process and the organized information has been minimizing. Teaching methods have changed and various online platforms, MOOCs, virtual classrooms has been popularized and these were aided by Virtual and Digital libraries and librarians can tap into this opportunity to health educate the users through e-learning and e-lending of resources.

Another opportunity can be found in Reference Question Service. Now people have less time to visit the library or totally denied access due to full closure of the traditional library and they want answer to their various query promptly and rightly. However, with the advancement of various Web 2.0 technology tools and medium of Communicative services like WhatsApp, hike, gtalk, messenger, skype chat etc various queries and information are passed easily. The modern library is well vast with these facilities and thus is coping along with phase of time. This is supported by the study of Grace A. Ajuwon et al 2020 that one of the unanticipated positive outcomes of the 16th professional conference for the association of health science librarian and information professional in Africa was the creation of a WhatsApp group in which personal development topics were posted daily to improve the leadership skills of the delegates. As the majority of the delegates that attended the conference were medical librarians and health information specialists, health workers, academic and representatives of government agencies. However, the modern libraries can use this opportunity to sensitize the members of the public.

Rapid Increase of electronic publishing: The increasing rate of electronic publishing during the era of COVID-19 pandemic has made a drastic change in the academic area. The initiative like Open Archives Initiative has opened the world of knowledge in front of users and to satisfy these facilities library has been designed and made access easily available. However, as there is more information that can be processed by any established mechanism as a result of infodemic, librarians can bring their information triage, vetting and organization skills to bear on the current crisis in new ways. Meanwhile, it's been reported that librarian 


\subsection{Challenges encountered by libraries when promoting health}

Due to global economic crisis libraries were also affected by lack of funding mainly for library programs, salaries, and resources. "Creative thought and action will be required to compensate for the already low pay of librarians, as well as the rising costs of materials and technology"(Hisle, 2002). This was corroborated by Chipungahelo et al. (2015) which stated financial constraint in their study as the major challenge facing libraries in promoting health literacy. According to Chipungahelo et al. (2015) funds allocated for the distribution of promotional materials to health centers are not enough. Funding is always needed to support training programs, for preparing of promotional materials including brochures, leaflets, training materials and others.

Another challenge is the ability of providing quality and reliable health information by various libraries. Considered a major threat to COVID-19- intervention efforts in Nigeria and elsewhere, the spread of incorrect information on the SARS-CoV-2 coronavirus, the causative agent of COVID 19, has become a subject of concern to Nigeria's experts on public health and infection prevention and control. Experts are faced with limited context-relevant information on the epidemiological patterns of COVID-19. Orban, (2005) argues that if librarians will not be able to select and disseminate quality and reliable information, people will rely on the information on social media and this will mislead the health information consumers and they may fail to make important health decisions because health information consumers depend on the health information obtained from libraries to make important decisions regarding their well-being.

Health illiteracy is a challenge among the people especially in rural community. Many people are not aware of the causative of many diseases including Coronavirus. Despite the efforts made by available libraries and NGOs, still efforts are needed to increase health literacy promotions especially in rural communities. Orban (2005) argues that librarians should work hard to increase awareness of diseases, their causes and preventive measures to meet the special information needs of health consumers with inadequate health literacy skills.

Finally, lack of policy has been identified has part of challenges faced by libraries. The study conducted by Metta et al. (2014) identified a number of challenges which hamper the efforts to combat diseases in Tanzania. They indicated that lack of specific policy and inadequate health systems have negative implication to the efforts to address non communicable diseases.

\section{Conclusion}

Although COVID-19 is an unprecedented pandemic for most of us in Sub Saharan Africa and Nigeria in particular, despite its late arrival, the COVID-19 outbreak has spread rapidly across the region in recent weeks and special attention on the efforts to curtail it need to be put in place because firstly the pandemic imposes a double burden to the government and the people and secondly, the death rates keep on increasing day by day. In spite of the fact that, libraries can be used to promote health, the effectiveness of the libraries in promoting health and curtailing the spread of COVID-19 pandemic in particular is not known in Nigeria. Librarian can be redeployed during emergency as Contact Tracers and Reserve Corps as used in the United States of America. Contact tracing is a rigorous but effective way of detecting persons who have been infected with infectious disease like COVID-19. The demand for information is more vital than ever now. Librarians are in a better position when it comes to evidenced based decision making.

\section{Recommendations}

It is recommended that, librarians should implement plans to offer remote service for example E-learning, Elending or support to remote teaching and sensitization programs. In cases of full closure of traditional library, librarians can be reassigned to other duties in other departments within their municipalities, for example using information management skills to support health and social services. Making library space and equipment available for other activities, such as printing personal protective equipment

Also, since the effectiveness of health promotion efforts is not known, libraries especially health libraries need to devise proper mechanisms to assess their efforts. Libraries should bank on the available opportunities such as ICTs tools and social media platforms which are increasingly becoming part of daily lives of people. Moreover, librarians should be proactive to update their skills and knowledge so as to cope with fast development of ICT.

However, governmental and non-governmental health organisations should deal with the infodemic (meaning there is more information) challenges arise in this era by employing librarians to bring their information triage, vetting and organization skills to bear on the current crisis in new ways. And libraries should be alive to fight against misinformation during this COVID-19 with accurate information and intensify on public enlightenment programs as government increases the testing capacity.

Governments of Nigeria and in all the nations of the world should imitate the government of San Francisco in the United State of America by assembling an army of librarians along side social workers, and medical 
students to find and warn anyone and everyone who may have been exposed to Covid-19 (Maanvi Singh, 2020). However, they need to put in place a system for tracing and tracking the contacts of people who have tested positive by exhibiting large-scale tracing efforts.

Finally, government at all levels should put a policy in place that will empower librarians as partners to combat this infectious disease and make them to be recognized as essential workers.

\section{References}

Africa-CDC. COVID-19 and resources/outbreak Africa CDC. [Online]. Available from: http://www.africacdc.org/covid-19-and-resources/ outbreak-briefs. [Cited on 18 March 2020].

Africa-CDC. COVID-19 and resources/outbreak Africa CDC. [Online]. Available from: http://www.africacdc.org/covid-19-and-resources/outbreak-briefs. [Cited on 18 March 2020].

AHILA- Tanzania Chapter", in IFLA World Library and Information Congress proceeding of the international conference in Cape Town, 15-21 August 2015, South Africa, pp. 1-7.

Anjorin, A.A. (2020). The coronavirus disease 2019 (COVID-19) pandemic: A review and an update on cases in Africa. Asian Pac J Trop Med; 13: 10.4103/1995-7645.281612.

Atanu G. \& Dhritiman B. (2018). Paradigm Shift of Libraries in Twenty first centuries:https://www.researchgate.net/publication/325594875.

Calderon, Cesar; Kambou, Gerard; Zebaze Djiofack, Calvin; Korman, Vijdan; Kubota, Megumi; Cantu Canales, Catalina. 2020. “Africa's Pulse, No. 21” (April), World Bank, Washington, DC. Doi: 10.1596/978-1-46481568-3. License: Creative Commons Attribution CC BY 3.0 IGO

Chipungahelo, M.S., Haruna, H., Ndege, J. and Lujenje, S. (2015), "Promoting Public Access to Health information: Experience of the Association for Health Information and Library in Africa,

Dodson, S. Good, S. Osborne, R.H. (2015), Health literacy toolkit for low- and middle-income countries: a series of information sheets to empower communities and strengthen health systems,

Emergency Committee regarding the outbreak of novel coronavirus(2019-nCov) (2020). http://www.who.int/news-room/detail/30-01-2020.statement-on-the-second-meeting-of-the-internationalhealth-rgulation-(2005)-emergency.committee-regarding-the-outbreak-of -novel-coronavirus-(2019 ncov). Accessed 1 Feb 2020

Femi A. \& Oyinade, T. (2017). 'Health Care Information Literacy: The Role of Librarians'. International Journal of Advanced Scientific Research and Development IJASRD, 04(03/11), pp.114-121

Grace A. Ajuwon et al.,(2020). Hosting the $16^{\text {th }}$ AHILA Conference in Ibadan Nigeria:Organisation, Achievements, Challenges and Lesson Learnt. Journal of EAHIL, 2020 vol16 (1):16-19 doi:1032

Ghosh, M. (2013), "Health literacy for all- an investigation into consortia and partnership amongst libraries to promote health care information in India" in World Library and Information Congress proceeding of the international conference, 2013, Singapore, pp. 1-11.

Hisle, W.L. (2002). Top issues facing academic libraries: A report of the focus on the future task force. College \& Research Libraries News, 63(10). Retrieved May 16, 2020 from http://www.ala.org/acrl/proftools/recruiting/topissuesfacing.

IFLA (n.d.). How libraries contribute to sustainable development and the SDG. IFLA ALP: Building Better Library Communities, IFLA.

Libschiltz, Q. (2004). A perfect Partnership-Librarians and literacy providers. Connecting magazine.

Maanvi Singh (2020). San Francisco Coronavirus outbreak/California/infections diseases/medical research/news.the guardian.com

Mahnaz Dar, (2020). Librarian volunteers help WHO make sense of COVID Information, https://www.libraryjournal.com/detailstory=librarian-volunteers-help-who-make-sense-of-Covidinformation.

McQueen, D.V., Manoncourt, E., Cartier, Y.N., Dinca, I. and Nurm, Ü. (2014), "The Transferability of Health Promotion and Education Approaches Between Non - communicable

Diseases and Communicable Diseases_-an Analysis of Evidence", AIMS Public Health, Vol. 1 No. 4, pp. $182-$ 198.

Metta, E., Msambichaka, B., Mwangome, M., Nyato, D.J., Dieleman, M., Haisma, H., Klatser, P. and Geubbels, E. (2014), "Public policy, health system, and community actions against illness as platforms for response to NCDs in Tanzania: a narrative review", Global Health Action. Vol. 7 Iss. s6.

Mnzava, E.E. and Katabalwa, A.S (2017), "The role of libraries in promoting health literacy for combating noncommunicable diseases in Tanzania", International Journal of Development and Sustainability, Vol. 6 No 7 , pp.443-450.

NCDC. An update of COVID-19 outbreak in Nigeria. [Online]. Available from: https://www.thenigerianvoice.com/news/285868/update-on-covid- 19-in-nigeria.html. [Cited on 14 March 2020]. 
Ntlotlang, T. and Grand, B. (2016), "The role of libraries in the dissemination of health information in Botswana", Library Review, Vol. 65 No. 4/5, pp. 320-349.

Nutbeam, D. (2000), "Health literacy as a public health goal: a challenge for contemporary health education and communication strategies into the 21st century", Health Promotion International, Vol. 15 No. 3, pp. 259267.

Nwafor-Orizu E. (2020). Health Literacy for Rapid Development in Nigeria. https://www.academia.edu. Retrieved 26 April 2020

Obidike, N.A. \& Nkechi, I. (2011), "The Library as an Effective Tool for Understanding the Health Status of Rural Communities in Nigeria”, Library Philosophy and Practice (e-journal). 675.

Orban, E. (2005), "Health Literacy: Challenges and Implications for Consumer Health Librarians", Indiana Libraries, Vol. 24 No. 3, pp. 2-6.

Osborne, H. (2012), Health Literacy From A to Z: Practical Ways to Communicate your Health Message, Jones \& Bartlett Learning, Burlington.

Parker, R. \& Kreps, G.L. (2005), "Library outreach: overcoming health literacy challenges", Journal of Medical Library Association, Vol. 93 No. 4. pp. 81.

Rootman M. (2012). An intersectoral approach for improving health literacy for Canada: a discussion paper. Vancouver, Public Health Association of British Columbia.

Sanders, L.M., Federico, S., Klass, P., Abrams, M.A. \& Dreyer, B. (2009), "Literacy and Child Health", Archives of Pediatrics \& Adolescent Medicine, Vol. 163 No. 2, pp. 131-140.

Tang, Y.H., Pang, S.M.C., Chan, M.F., Yeung, G.S.P. \& Yeung, V.T.F. (2008), "Health literacy, complication awareness, and diabetic control in patients with type 2 diabetes mellitus", Journal of Advanced Nursing, Vol. 62 No. 1, pp. 74-83.

United Nations Economic and Social Council (ECOSOC) (2010), Health literacy and the Millennium Development Goals: United Nations Economic and Social Council (ECOSOC) regional meeting background paper (abstracted). Journal of Health Communication, Vol. 15 Suppl 2, pp. 211-223.

W.H.Organazayion "Rolling Updates of Coronavirus diseases (COVID-19). Available at: https://www.who.int/emergencies/disease/novel-coronavirus-2019/event-as-they-happeb. Accessed on 29 April 2020.

WHO 2013. Health Literacy: the solid facts edited by kickbusch.I et.al WHO Regional office for Europe, UN City, Marmorvej51DK-2100 Copenhagen, Denmark.

WHO, Novel Coronavirus-China2020. http://www.who.int/csr/don/12-january-2020-novel coronavirusChina/en/. Accessed 1 Feb 2020.

WHO, statement on the second meeting of the International Health Regulations (2005).

WHO. Novel coronavirus (COVID-19) situation. [Online]. Available from: https://experience.arcgis.com/experience/685d0ace521648f8a5beeee1b9 125cd. [Cited on 18 March 2020].

WHO. Novel coronavirus (COVID-19) [Online]. Available from:https://experience.arcgis.com/experience/685d0ace521648f8a5beeee1b9 125cd. [Cited on $18 \mathrm{March}$ 2020].

WHO-Afro. Senegal reports first COVID-19 case: WHO Africa. [Online]. Available from: https://www.afro.who.int/news/senegal-reports-firstcovid- 19-case. [Cited on 14 March 2020].

Wickline, M.A. \& Rosenthal, C.A. (2010), "Health Literacy: Collaborating to Educate Professionals", Journal of Consumer Health On the Internet, Vol. 14 No. 2, pp. 184-192.

WMHC, Wuhan Municipal Health and Health Commission. Briefing on the Current Pneumonia Epidemic Situation in our city. 2020. http://wjw.wuhan.gov.cn/front/web/showDetail/2019123108989. Accessed 1 Feb. 2020.

World Health Organisation 2009. ECOSOC Annual Ministerial Review Regional Preparatory Meeting on Promoting Health Literacy Beijing, China, 29-30 April 2009 Background note

Worldmeter, "Coronavirus (COVID-19) pandemic. Available at http://www.worldometer.info/coronavirus/II Countries, "Worldmeter (2020)., p. Worldmeter (2020)., Accessed on 29 April 2020. 